\title{
Reduction in energy efficiency induced by expression of the uncoupling protein, UCP1, in mouse liver mitochondria
}

\author{
PEDRO GONZÁLEZ-MUNIESA, FERMÍN I. MILAGRO, JAVIER CAMPIÓN and J. ALFREDO MARTÍNEZ
}

Department of Physiology and Nutrition, University of Navarra, Pamplona (Navarra), Spain

Received November 24, 2005; Accepted January 12, 2006

\begin{abstract}
Uncoupling Protein 1 (UCP1) is an inner mitochondrial membrane protein, uniquely expressed in brown adipocytes, which uncouples the mitochondrial respiration impairing ATP production and energy efficiency. The aim of the present study was to express UCP1 in liver mitochondria using a non-viral system in order to affect energy utilization. The effect of ectopic protein expression on liver energy metabolism, which was evaluated $42 \mathrm{~h}$ after DNA transfer, showed that mitochondria expressing UCP1 presented decreased ATP production, lasted more time in membrane potential state 3 , and consumed more molecular oxygen to produce the same amount of ATP than the control group. In summary, the successful functionality of the mitochondrial protein, UCP1, after hydrodynamic delivery is a novel and significant finding. This approach could be useful to ectopically express mitochondrial proteins and, in this particular case, to manage metabolic disorders related to energy efficiency and expenditure, such as obesity.
\end{abstract}

\section{Introduction}

Mitochondria are the cellular organelles where respiration and ATP synthesis occur (1). Dysfunctions in these processes may be related to disorders in heat dissipation and energy metabolism, such as obesity (2). The current definition of obesity is an excessive accumulation of fat due to an inequality in thermodynamic energy balance (3). This disequilibrium has driven to an increasing worldwide prevalence of obesity,

Correspondence to: Dr J. Alfredo Martínez, Department of Physiology and Nutrition, University of Navarra, 31008 Pamplona, Spain

E-mail: jalfmtz@unav.es

Abbreviations: UCP, uncoupling protein; BAT, brown adipose tissue; RT-PCR, reverse transcription-polymerase chain reaction; BLI, bioluminescent imaging; PBS, phosphate-buffered saline; i.p., intraperitoneal; BSA, bovine serum albumin; RCR, respiratory control ratio; DiSC3 5, 3,30-dipropylthiadicarbocyanine iodide

Key words: energy metabolism, Uncoupling protein-1, gene delivery, hydrodynamics, ATP, UCP leading to a lower life expectancy and higher risk of developing type 2 diabetes or metabolic syndrome $(4,5)$.

In addition to inadequate food habits and sedentary lifestyles, more than 430 genes or chromosomal regions have been associated with obesity (6). Therefore, in recent years, the management of excessive weight gain has become not only a therapeutic target but also a research goal using different approaches to understand and influence energy efficiency processes. Numerous studies have been published describing different molecules playing a role in the genetic control of energy balance (or imbalance) (5), including some putative and suitable objectives for gene therapy, such as the family of uncoupling proteins $(7,8)$.

Gene therapy, defined as the transfer of genetic material to cells in order to reach a therapeutic target, has been developed as a practical approach with a potential impact on tissue biological functions (9). The use of gene transfer technologies in animal models of human diseases and pilot clinical studies is aiding the understanding, prevention and treatment of different genetic diseases, such as cancer (10) and diabetes (11). Therapeutic genes can be incorporated into target cells without any protection, as naked DNA (12), or enveloped by molecular constructs named vectors, which can be viral $(10,13)$ or non-viral (14). The specificity of the transduction depends on the promoter and/or on the delivery technique. Thus, there are tissue-specific techniques, such as direct injection into muscle $(15,16)$ or hydrodynamic delivery, a liver-specific technique administrating a rapid intravenous injection of a large aqueous volume of a nucleic acid solution into the tail of the animal $(17,18)$.

The family of uncoupling proteins (UCPs) constitutes at least six members which are candidates in regulating energy expenditure (19-21). Thus, UCPs are mitochondrial anion carrier proteins (22), whose main function appears to consist of uncoupling ATP production by causing proton leakage from mitochondria (7). Consequently, while these proteins have a very well-documented relationship with energy metabolism and, specifically, obesity (23), their overall functions are still poorly known. It has been reported that UCPs are also important for the inhibition of reactive oxygen species (ROS) formation or for the prevention of atherosclerosis and inflammation (24), although UCP1 and UCP2 do not appear to participate in the in vitro production of superoxide from respiring mitochondria (25). Other studies have demonstrated that UCPs are related to an increase in life expectancy (26) and prevention of glucose-induced neuronal oxidative stress 
and programmed cell death (27). In addition, some studies concerning UCP1 $(16,28)$, UCP2 (15) or UCP3 (29) gene transfer have shown a clear relationship between these proteins and the bioenergetic processes in the mitochondria.

The most documented component of the UCP family is UCP1 or thermogenin (24). This inner mitochondrial membrane protein is uniquely expressed in BAT (30) and seems to be physiologically relevant for cold- and diet-induced thermogenesis $(31,32)$. Moreover, UCP1 interacting with free fatty acids (33) catalyses the thermogenic net transfer of protons from the mitochondrial intermembrane space to the matrix (24), making an important contribution to resting energy expenditure and body weight regulation in small mammals, although it appears to be of relatively lower importance in large mammals (24).

Considering these findings and observations, our purpose was to ascertain the viability of a nonviral gene transfer (like hydrodynamics) for achieving an ectopic expression of UCP1 in liver in order to impair the mitochondrial energy efficiency. In order to do this, different bioenergetic markers of metabolism were assessed.

\section{Materials and methods}

Animals. Fourteen male FVB mice (Harlan, Spain) of $<30 \mathrm{~g}$ were kept at $23^{\circ} \mathrm{C}$ on a $12: 12$ light-dark cycle with free access to food and water. All animal manipulations were made in accordance with European Community guidelines for the use of laboratory animals and the Ethics Committee for Animal Experimentation (CEEA) of the University of Navarra.

Plasmid and DNA transfer method. After an adaptation period, the mice received, in approximately $6 \mathrm{sec}$, a bolus injection in the tail vein with $10 \%$ of their weight $(\mathrm{g})$ in volume $(\mathrm{ml})$ of a complex containing Mirus Polymer Solution, Mirus Delivery Solution and $20 \mu \mathrm{g}$ of DNA according to the manufacturer's instructions (Mirus Corporation, WI, USA). The applied DNA plasmid utilized in each case was plasmid pCMV-Luc (and empty plasmid pCMV as control) for in vivo bioluminescent imaging (BLI), plasmid pCMV-LacZ (and empty plasmid pCMV as control) for Bgal staining, and plasmid pXC1 (UCP1 group) or empty plasmid pXAV2 (control group) for measurement of the functionality of transferred UCP1. The plasmid ( $\mathrm{pXC1}$ ) contained pXAV2 and rat UCP1 cDNA under the control of the CMV promoter (16).

In vivo bioluminescent imaging (BLI). In vivo BLI was performed using an IVIS Imaging System (Xenogen, CA, USA). Images and measurements of bioluminescent signals were acquired and analyzed using Living Image (Xenogen) software. Mice were anaesthetized and shaved before receiving

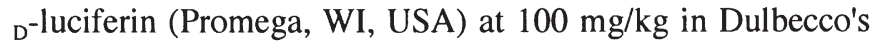
PBS (D-PBS; Gibco, Invitrogen Corporation, UK) by i.p. injection $10 \mathrm{~min}$ before imaging. All images were acquired with a 1-min exposure.

LacZ activity. Expression from the LacZ transgene, $42 \mathrm{~h}$ after the injection, was monitored by $\beta$-galactosidase staining on cryostat liver sections $(10-20 \mu \mathrm{m})$. Liver sections were fixed for 10 min with $0.5 \%$ glutaraldehyde, washed three times with $\mathrm{PBS}$ and stained for $4-16 \mathrm{~h}$ at $37^{\circ} \mathrm{C}$ in $5 \mathrm{mM} \mathrm{K}{ }_{3} \mathrm{Fe}(\mathrm{CN})_{6}$, $5 \mathrm{mM} \mathrm{K}_{4} \mathrm{Fe}(\mathrm{CN})_{6}, 1 \mathrm{mM} \mathrm{MgCl}$ and $1 \mathrm{mg} / \mathrm{ml} \mathrm{X}$-gal in PBS. For tissue sections, liver slices were embedded in OCT (Sakura Finetek Europe B.V., The Netherlands) before freezing.

Reverse transcription-PCR (RT-PCR) analysis. RNA was extracted according to a standardized procedure with Trizol using the instructions of the supplier (Life Technologies, Inc, UK). The UCP1 mRNA expression was confirmed by RTPCR using the following primers: 5'-CTCACCTTTGAGCT CCTC-3'(sense) and 5'-CTGATTTGCCTCTGGATG-3' (antisense). PCR was run for 32 cycles and the melting temperature was $55^{\circ} \mathrm{C}(15)$.

Mitochondrial preparations. Approximately $42 \mathrm{~h}$ after DNA transfer, livers were carefully minced with scissors and rinsed thoroughly in an isolation buffer (8-10 ml/g tissue) containing $250 \mathrm{mM}$ sucrose, $1 \mathrm{mM}$ EDTA and $5 \mathrm{mM}$ MOPS, $\mathrm{pH}=7.4$. The tissue was further homogenized in a Potter Elvehjem homogenizer as previously reported (34). Each step of the mitochondrial isolation was performed at $4^{\circ} \mathrm{C}$. The homogenate was centrifuged for $10 \mathrm{~min}$ at $1000 \mathrm{x} \mathrm{g}$, and the supernatant was centrifuged for $10 \mathrm{~min}$ at $9000 \mathrm{x} \mathrm{g}$. The mitochondrial pellet was resuspended in an approximate volume of $2 / 5$ of the initial volume containing $250 \mathrm{mM}$ sucrose, $5 \mathrm{mg} / \mathrm{ml} \mathrm{BSA}$ and $5 \mathrm{mM}$ MOPS, $\mathrm{pH}=7.4$. The homogenate was again centrifuged for $10 \mathrm{~min}$ at $1000 \mathrm{x} \mathrm{g}$ and the supernatant was centrifuged for $10 \mathrm{~min}$ at $9000 \mathrm{x} \mathrm{g}$. The mitochondrial pellet was resuspended in a minimal volume $(\sim 0.5 \mathrm{ml})$ and mitochondrial protein content was assayed by the pyrogallol red method (35). Mitochondrial membrane potential, respiration rate and ATP measurement were evaluated using fresh mitochondria, with some aliquots being frozen for further analysis of protein expression by inmunoblotting, as described elsewhere (36).

Western blot analysis. Mitochondrial fractions were sonicated (Branson Sonifier 250, CT, USA) and normalized for protein prior to loading onto gel for Western blot analysis. Samples were electrophoretically separated in $12 \%$ SDS-PAGE and electrotransferred to nitrocellulose membranes (Schleicher \& Schuell BioScience, Inc., NH, USA). Membranes were incubated overnight with affinity-purified rabbit polyclonal antibody to UCP1 (UCP11-A; Alpha Diagnostic Intl., Inc., TX, USA). Secondary goat anti-rabbit IgG-HRP (Santa Cruz Biotechnology, Inc., CA, USA) was added for one hour of incubation and blots were developed by chemiluminescent detection (Pierce Biotechnology, Inc., IL, USA).

Mitochondrial proton leak measurements. Respiration and membrane potential measurements were performed under the same conditions, as previously described (37). Mitochondrial oxygen consumption was determined simultaneously and in parallel with changes in membrane potential. For all measurements, respiration medium containing $75 \mathrm{mM} \mathrm{NaCl}$, $1 \mathrm{mM}$ EGTA, $2 \mathrm{mM} \mathrm{Na} \mathrm{HPO}_{4}, 1 \mathrm{mg} / \mathrm{ml} \mathrm{BSA}$ and $10 \mathrm{mM}$ MOPS, $\mathrm{pH}=7.0$, was applied.

Oxygen consumption. Mitochondrial respiration was measured using a Hansatech (UK) Clark-type oxygen electrode (Respire 


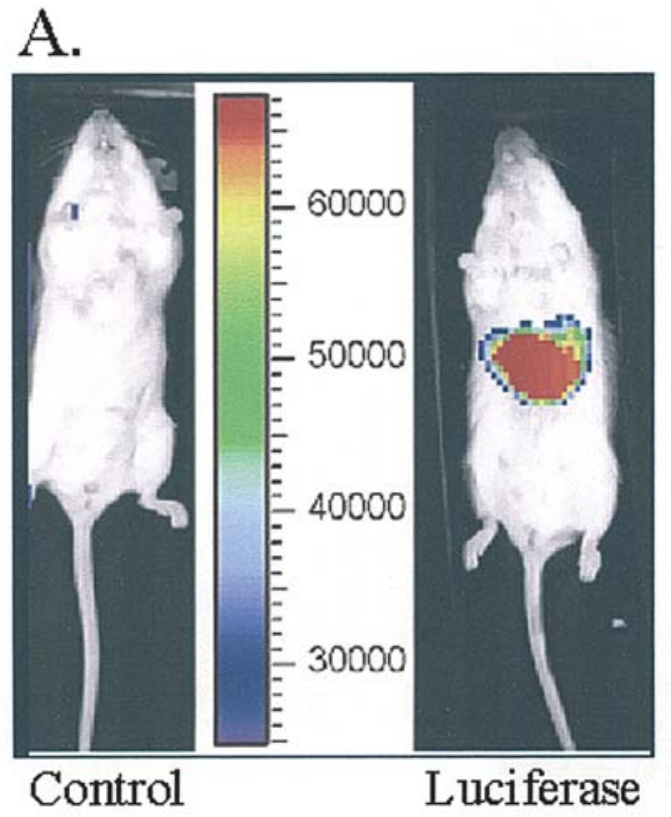

B.

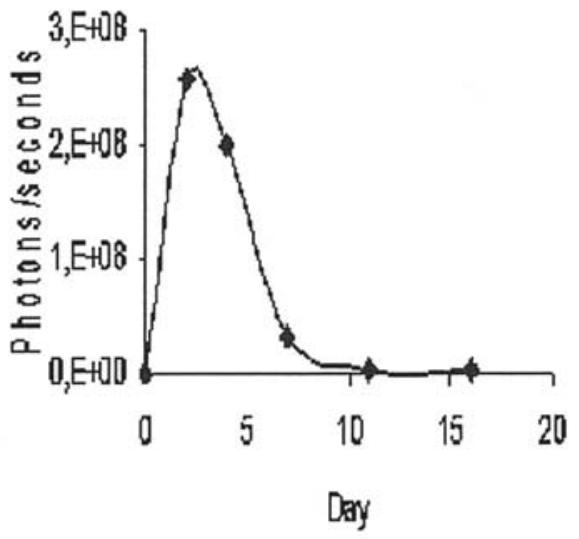

Figure 1. Hydrodynamics effectivity tissue assessment. A, in vivo bioluminescent imaging allows the measurement of luciferase expression and its localization in CMV-Luc-treated mice. Data were obtained 4 days after the intravenous injection. B, graph showing luciferase expression (units: photons/sec) $2,4,7,11$ and 16 days after gene transfer delivery.

1 model), whose incubation chamber was thermostatically set at $25^{\circ} \mathrm{C}$ and magnetically stirred. Each sample was assessed by incubating $1.0 \mathrm{ml}$ of respiration medium with $0.5 \mathrm{mg}$ mitochondrial protein in the electrode chamber. Respiratory rates were calculated from the chart recordings using an oxygen solubility coefficient of $253 \mathrm{nmol} \mathrm{O} / 2 / \mathrm{ml}$ buffer at $25^{\circ} \mathrm{C}$ and 1 atmosphere pressure (37).

Membrane potential. Mitochondrial membrane potential was monitored using the potential-sensitive fluorescent dye DiSC3 5 (3,30-dipropylthiadicarbocyanine iodide; Molecular Probes, OR, USA), following a previously described protocol (16).

ATP measurement. ATP production was quantified by bioluminescence following the manufacturer's instructions (Enliten rLuciferase/Luciferin reagent; Promega corporation, WI, USA), in a Sirius luminometer (Berthold Detection Systems, TN, USA).

Statistical analysis and presentation of results. The data are presented as mean \pm SD, and difference significance was evaluated using the Wilcoxon test where relevant. All analyses were performed using the SPSS version 11.0 statistical package (SPSS, Inc., IL, USA). A p-value of $<0.05$ was considered as statistically significant.

Reagents. Rotenone, succinate, ADP, CCCP, BSA and MOPS were purchased from Sigma (MO, USA). Other chemicals were from Panreac Química, S.A. (Spain).

\section{Results}

Assessment of the efficiency of hydrodynamic delivery to the liver. Luciferase expression in mouse liver, as detected by BLI (Fig. 1A), indicated that the gene delivery method was suitable

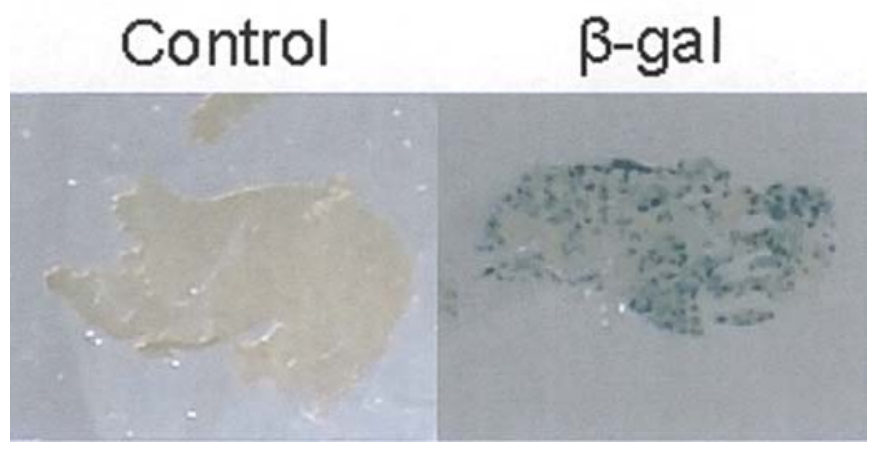

Figure 2. Hydrodynamics effectivity liver tissue assessment. Liver slices of $10 \mu \mathrm{m}$ were cut in cryostat and prepared for X-gal staining as described under 'Materials and methods'. Liver slices from 2 different mice (one control and one $\mathrm{X}$-gal mouse) were visualized through a $3 \mathrm{x}$ camera zoom. The blue point indicates the liver cell expressing $\beta$-gal.

for reaching the target organ and for obtaining adequate gene expression. In vivo analysis allowed, in addition, definition of the period of time for measuring gene expression and functionality (Fig. 1B). According to these results, a 42-h period was finally chosen.

$\mathrm{X}$-gal staining showed that $\mathrm{B}$-galactosidase expression was detected in at least $20 \%$ of the liver cells (extensive X-gal staining cells) $42 \mathrm{~h}$ after the single injection (Fig. 2). These two methods confirmed the suitability both of the hydrodynamic delivery method and the FVB mouse strain (38) for these experiments.

Appraisal of the mRNA expression and UCP1 protein. UCP1 mRNA expression levels were analyzed in a representative sample of livers from the UCP1 and control groups. Brown adipose tissue (BAT) was used as positive control and water as negative control. UCP1 mRNA was not found in control livers, as described by other authors (39), whereas its expression 


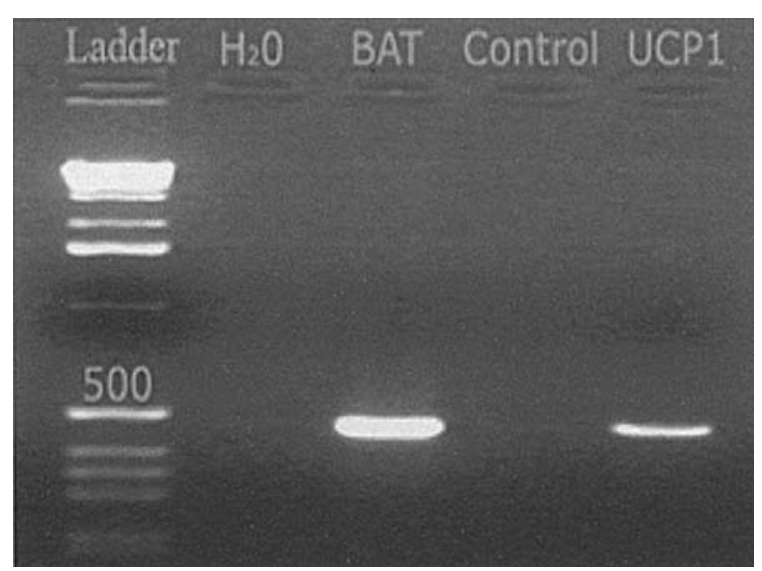

Figure 3. UCP1 mRNA expression confirmation in livers from the UCP1 group. A, UCP1 m-RNA expression in liver was measured by RT-PCR as described under 'Materials and methods'. Lane 1, $1 \mathrm{~kb}$ Plus DNA ladder (Invitrogen Corporation, UK) showing a band of $500 \mathrm{bp}$. Lane 2, water sample as negative control. Lane 3, BAT sample as positive control. Lane 4, mouse control group. Lane 5, mouse selected from the UCP1-group showing a band similar to the positive control and with the correct height in comparison with ladder.

was detected in livers from the UCP1 group and in the BAT sample (Fig. 3).

Inmunoblotting was performed in six samples and a representative gel is presented (Fig. 4). A marked band between 32 and $33 \mathrm{kDa}$ was observed by Western blotting in isolated liver mitochondria from UCP1-transfected mice and in BAT mitochondria, whereas it was not detected in isolated liver

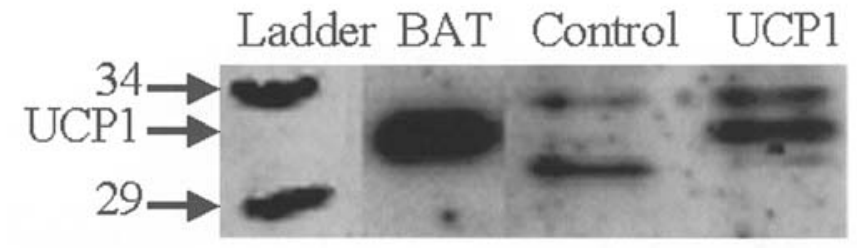

Figure 4. UCP1 expression confirmation in the liver mitochondria of the UCP1 group. UCP1 protein was measured in mitochondrial protein extract from the liver by Western blotting as described in 'Materials and methods'. Lane 1, ladder showing a band of $34 \mathrm{kD}$ and another one of $29 \mathrm{kD}$. Lane 2, BAT sample as positive control for UCP1. Lane 3, mouse chosen from the control group. Lane 4, mouse selected from the UCP1 group showing a band of 32-33 kd and with the correct height in comparison with ladder and positive control.

mitochondria from the control group. This analysis confirmed that a single administration of the plasmid by using a hydrodynamic method via the tail vein resulted in the expression of the analyzed protein at $42 \mathrm{~h}$ post injection.

Effect of UCPI expression on liver mitochondrial proton leakage. Mitochondrial membrane potential $(\Delta \Psi)$ and thermogenesis (oxygen consumption and the production of ATP) processes were studied in isolated liver mitochondria from the UCP1 and control groups. Thus, the expression of UCP1 diminished the ATP production in the UCP1 group (Fig. 5A) in comparison with the control group $(0.020 \pm 0.013 \mathrm{~mol}$ ATP/g protein, $\mathrm{n}=7$, vs. $0.027 \pm 0.014 \mathrm{~mol} \mathrm{ATP} / \mathrm{g}$ protein, $\mathrm{n}=7 ; \mathrm{p}=0.021$ ).
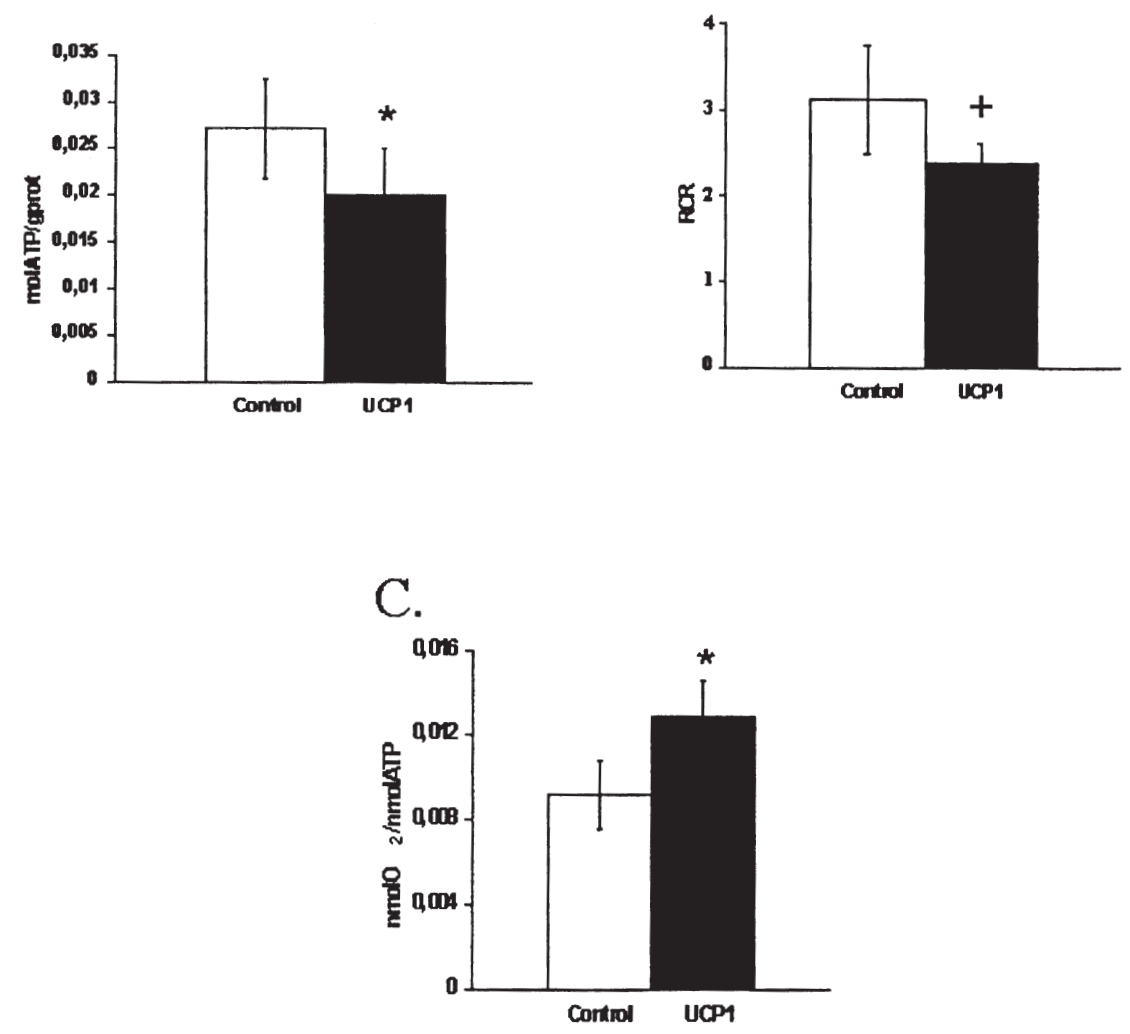

Figure 5. Energy efficiency reduction in the UCP1 group. Measurements realized in isolated liver mitochondria from the UCP1 group (filled column) and control group (empty column). A, the content of ATP. Columns are given as mol ATP/g protein \pm SD ( $n=7),{ }^{*} p<0.05$. B, respiration control ratio (RCR). Columns are given as RCR (no units) $\pm \mathrm{SD}(\mathrm{n}=6),{ }^{+} \mathrm{p}=0.058$. $\mathrm{C}$, energy efficiency may be explained by the oxygen consumption needed to produce an equal amount of ATP. Columns are given as nmolO2/nmolATP $\pm \operatorname{SD}(n=6),{ }^{*} \mathrm{p}<0.05$. 


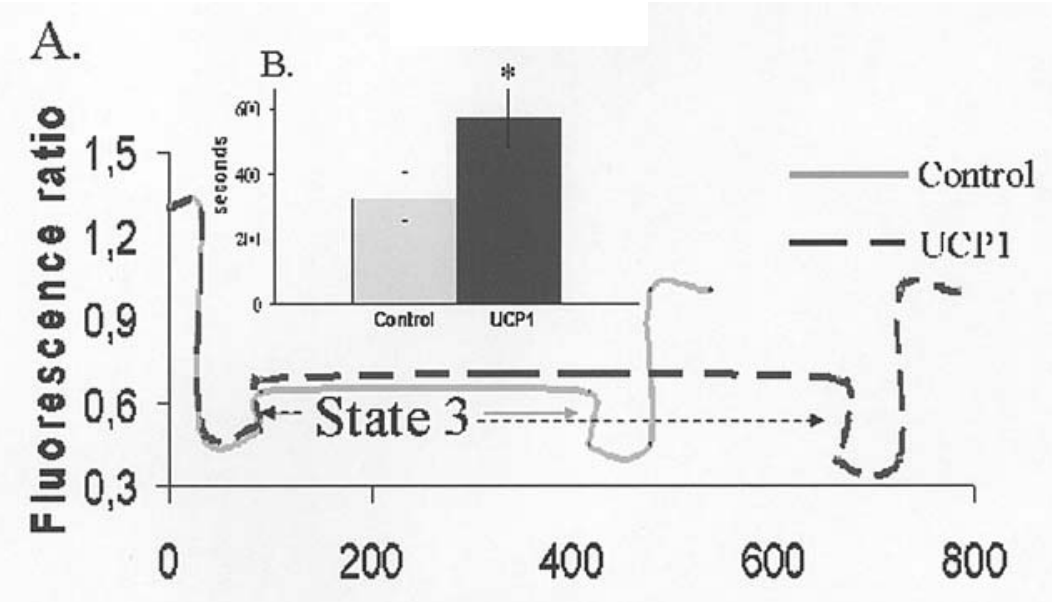

Accumulated time (seconds)

Figure 6. Membrane potential. A, membrane potential of the liver mitochondria was measured as described in 'Materials and methods' from the control group (gray line) and UCP1 group (black dotted line). Lines are given as fluorescence ratio [ $\mathrm{mV}$ of membrane potential normalized by the uncoupled state (with $\mathrm{CCCP})]$ and accumulated time $(\mathrm{min}),(\mathrm{n}=5)$. B, time spent in state 3 from the control group (gray column) and UCP1 group (black column). Columns are given as $\sec \pm \operatorname{SD}(\mathrm{n}=5),{ }^{*} \mathrm{p}<0.05$.

Respiration control ratio ( $\mathrm{RCR}$ ) assessment showed a tendency to be lower in the group expressing ectopic UCP1 (Fig. 5B) than in control $(2.39 \pm 0.52, \mathrm{n}=6$, vs. $3.12 \pm 1.53, \mathrm{n}=6$; $\mathrm{p}=0.058$ ), which was attributed to a simultaneous increase in state 4 and decrease in state 3 in the UCP1 group (data not shown).

Regarding oxygen consumption, the UCP1 group needed more molecular oxygen (Fig. 5C) to produce the same amount of ATP as control mice did $(0.0129 \pm 0.0041 \mathrm{nmol}$ $\mathrm{O}_{2} / \mathrm{nmol}$ ATP, $\mathrm{n}=6$, vs. $0.0092 \pm 0.0040 \mathrm{nmol} \mathrm{O} / \mathrm{nmol} \mathrm{ATP}$, $\mathrm{n}=6 ; \mathrm{p}=0.037$ ), suggesting a diminished energy efficiency in the UCP1 group.

Finally, although no significant changes in the different states of membrane potential were observed, there was an increase of approximately $75 \%$ in the duration of state 3 in the UCP1 group (Fig. 6B) in comparison with the control group $(574 \pm 204 \mathrm{sec}, \mathrm{n}=5$, vs. $327 \pm 166.5 \mathrm{sec}, \mathrm{n}=5 ; \mathrm{p}=0.021)$, which suggests an impairment in ATP synthesis in UCP1transferred animals.

\section{Discussion}

The present study demonstrates that UCP1 gene transfer in hepatocytes by using hydrodynamic-based transfection affects energy utilization in liver mitochondria of FVB mice.

The liver is a very interesting and suitable organ as a target for gene therapy because it is well irrigated and vascularized, is highly metabolically active, and is involved in glucose and lipid homeostasis $(10,40)$ In this context, whereas viral vectors currently present limited usefulness in gene therapy due to their pathogenic risks, hydrodynamic-based procedures have a well-documented liver expression, no limitation in DNA size, an adequate safety level, are cost-effective and reach high levels of gene expression in hepatocytes $(17,18)$.

$\mathrm{UCP} 1$ is a very interesting target gene for enhancing energy utilization and substrate oxidation. Thus, gene therapy using UCP1 has been applied in rodents in order to find a therapeutic approach for obesity and other energy disorders (11). However, although a hydrodynamic-based method is the simplest, the present study is apparently the first to utilize this approach to transfer UCP1 in rodents for altering energy metabolism, owing to its limitations regarding transfection efficiency and level of expression compared with viral vectors.

Figs. 1 and 2 show that both methods (BLI and Lac Z activity) confirmed the suitability both of the hydrodynamic method and the FVB mouse strain for these experiments, serving to acquire a better understanding of the expression level and to select the time of expression. As has been described by other authors (41), the best results are obtained with administration volumes of $2-3 \mathrm{ml}$ per $30 \mathrm{~g}$ mouse and injection times of less than $8 \mathrm{sec}$. Regarding DNA dose, gene expression reaches a saturation level at approximately $5 \mu \mathrm{g}$ of injected DNA per mouse.

RT-PCR and Western blotting showed measurable levels of UCP1 mRNA (Fig. 3) and UCP1 protein (Fig. 4), respectively. This initial approach validated the gene delivery method and the artificial polymer complex chosen for the ectopic expression of UCP1 in mouse liver mitochondria.

After confirming the ectopic expression of UCP1, the mitochondrial bioenergetics were analyzed. The production of ATP is the final objective of aerobic respiration due to the mitochondrial proton gradient generated by complexes of the respiratory chain used by ATP synthase in order to phosphorylate ADP (42). A proton leak, such as with UCP1, consumes part of the gradient and lowers ATP synthesis (43). As expected, in the present study, the measurements of ATP showed that the expression of ectopic UCP1 results in a decreased production of ATP when compared with the control group, suggesting that our ectopic UCP1 was functionally operative. These results are in accordance with in vitro data obtained by our group in HepG2 cells (14), but also by another group in a diet-induced obese mouse model (11).

Different steps participate in mitochondrial respiration, which are designated as states (37). State 2 is characterized by the presence of substrate, absence of ADP and a slow rate of oxygen uptake. The addition of a given amount of ADP to 
this suspension of nonphosphorylating mitochondria stimulates oxygen consumption and marks the beginning of State 3 concomitant with increased proton transport. This state is characterized by maximal phosphorylation and oxygen consumption rates. State 4 starts when the ADP amount added to the suspension is transformed into ATP molecules and no more ADP is available for phosphorylation. RCR, a respiratory parameter linking states 3 and 4, quantifies the coupled state of mitochondria and can be used to compare mitochondrial populations obtained from a given tissue in the same physiological status and isolation procedure (44).

In the present study, RCR tended to be lower in the group overexpressing UCP1, which can be attributed to an increase in inner proton permeability during state 4 . Nevertheless, oxygen consumption from the UCP1-transferred group showed no statistical differences in states 3 and 4 when compared with the control group (Fig. 3B), confirming the data previously published in an earlier study in muscle (16).

The energy efficiency of liver mitochondria was affected by the expression of ectopic UCP1; i.e., the control mitochondria consumed less molecular oxygen to produce the same amount of ATP than the group of mice that ectopically expressed UCP1 in their livers. In the mitochondria expressing UCP1, the uncoupling protein reduced energy efficiency due to increased proton transport from the intermembrane space to the matrix. The respiratory chain consumes oxygen and transports protons from the matrix to the intermembrane space, and these protons and the potential difference originated is used by ATP synthase to produce ATP. However, when UCP1 is expressed (naturally or ectopically), the protons and the potential difference used by ATP synthase are substantially reduced due to the proton flux mediated by this protein to produce heat. Therefore, the UCP1 group should need more oxygen consumption (more energy expenditure) to maintain the same activity level as the control group (i.e., reduced energy efficiency). At this time, a surplus of energy substrates (free fatty acids, glucose) should be mobilized in order to maintain metabolic energy production in the usable form of ATP.

The fluorescence intensity of the dye DiSC3 5 was used as an indicator of potential $(\Delta \Psi)$ in biological membranes. This method is based on the potential-dependent partitioning of the dye between the mitochondria and the medium, leading to a decrease in the fluorescence ('quenching') with increasing $\Delta \Psi(45,46)$ The addition of succinate (state 2) activates the respiratory chain by increasing the membrane potential (proton transport to the intermembrane space) and diminishes fluorescence intensity. The addition of ADP (state 3 ) produces the inverse effect and, when ADP is consumed by the mitochondria respiratory chain (state 4 ), the proton flux is reactivated producing nearly the same reduction in fluorescence as in state 2 . Our results show similar fluorescent activity in all respiratory states between control and UCP1 groups. When present, UCP1 is continuously translocating protons and reducing the membrane potential, diminishing ATP production. This is reflected in the slowing down of ADP consumption (state 3 duration, Fig. 4B), which is longer in UCP1 transfected mitochondria than in those of the control group. Consequently, if mitochondria expressing UCP1 spend more time consuming the same quantity of ADP (which can be assumed to produce the same quantity of ATP), it should be concomitant with increases in oxygen consumption and energy expenditure (47).

Hence, a greater heat loss induced by UCP1 DNA transfer may be consistent with higher energy expenditure, and could have potential applications in the understanding of energy efficiency mechanisms as well as in the manipulation of energy homeostasis. There are several experiments concerning uncoupling proteins, either in animals $(11,16,48)$ or in cells (14), supporting the use of UCPs in gene therapy as a potential tool for controlling different diseases related to energy homeostasis, but there has been no report using the cheap and simple hydrodynamic-based procedure. Our experiments demonstrate that ectopic UCP1 expression in the liver affects mitochondria energy metabolism by decreasing the energy efficiency related to thermogenesis and body weight homeostasis, and provides additional data about the mechanisms of action of this protein.

In summary, the successful expression of UCP1 (a mitochondrial protein) in mouse liver after a single injection in the tail vein using a hydrodynamic method, showed changes in bioenergetic properties of isolated liver mitochondria and in energy efficiency. These results suggest that UCP1 gene transfer in mouse liver by hydrodynamic-based procedures could be a useful approach, by dissipating energy surplus, to understand and manage metabolic disorders related to energy efficiency and expenditure in mice, and confirms that gene therapy is expected to be useful in the treatment of diseases such as obesity.

\section{Acknowledgements}

The technical assistance of V. Ciaurriz and A. Lorente is gratefully acknowledged, as well as Dr E. Rial for the opportunity to learn some measurements of mitochondrial bioenergetics in his laboratory. The pXAV2 plasmid and rat UCP1 cDNA were kindly provided by Dr Novo (Department of Genetics, University of Navarra) and Dr Ricquier (CNRS UPR 9078, Faculté de Médecine Necker-Enfants Malades, Paris, France), respectively. Also, Dr B. de Fanti is credited for careful reading of the English version. Pedro GonzálezMuniesa holds a predoctoral grant from Danone Institute. This work was financially supported by Special Line of Investigation: Nutrition and Obesity (University of Navarra).

\section{References}

1. Darley-Usmar VM, Rickwood D and Wilson MT: Mitochondria: A practical approach. IRL Press, Oxford, UK, 1987.

2. Weissig V: Mitochondrial-targeted drug and DNA delivery. Crit Rev Ther Drug Carrier Syst 20: 1-62, 2003.

3. WHO/OMS Consultation group: Obesity: Preventing and managing the global epidemic. Report of a WHO consultation. World Health Organ Tech Rep Ser 894: 1-253, 2000.

4. World Health Organization, accessed Jan 2005: http://www. who.int/nut/obs.htm.

5. Bays HE: Current and investigational antiobesity agents and obesity therapeutic treatment targets. Obes Res 12: 1197-1211, 2004.

6. Marti A, Moreno-Aliaga MJ, Hebebrand J and Martinez JA: Genes, lifestyles and obesity. Int J Obes Relat Metab Disord 28: S29-S36, 2004.

7. Erlanson-Albertsson C: The role of uncoupling proteins in the regulation of metabolism. Acta Physiol Scand 178: 405-412, 2003. 
8. Berentzen T, Dalgaard LT, Petersen L, Pedersen O and Sorensen TI: Interactions between physical activity and variants of the genes encoding uncoupling proteins -2 and -3 in relation to body weight changes during a 10-y follow-up. Int J Obes Relat Metab Disord 29: 93-99, 2005.

9. Campion J, Milagro FI and Martinez JA: Genetic manipulation in nutrition, metabolism, and obesity research. Nutr Rev 62 : 321-330, 2004.

10. Prieto J, Herraiz M, Sangro B, Qian C, Mazzolini G, Melero I and Ruiz J: The promise of gene therapy in gastrointestinal and liver diseases. Gut 52: ii49-ii54, 2003.

11. Ishigaki Y, Katagiri H, Yamada T, Ogihara T, Imai J, Uno K, Hasegawa $Y$, Gao J, Ishihara $\mathrm{H}$, Shimosegawa T, Sakoda $\mathrm{H}$, Asano $\mathrm{T}$ and Oka Y: Dissipating excess energy stored in the liver is a potential treatment strategy for diabetes associated with obesity. Diabetes 54: 322-332, 2005.

12. Wolff JA, Malone RW, Williams P, Chong W, Acsadi G, Jani A and Felgner PL: Direct gene transfer into mouse muscle in vivo. Science 247: 1465-1468, 1990.

13. Monahan PE, Joss K and Sands MS: Safety of adeno-associated virus gene therapy vectors: A current evaluation. Expert Opin Drug Saf 1: 79-91, 2002.

14. González-Muniesa P, Milagro FI, Campión J and Martínez JA: Ectopic UCP1 gene expression in HepG 2 cells affects ATP Production. J Physiol Biochem 61: 389-394, 2005.

15. Marti A, Larrarte E, Novo FJ, Garcia M and Martinez JA: UCP2 muscle gene transfer modifies mitochondrial membrane potential. Int J Obes Relat Metab Disord 25: 68-74, 2001.

16. Larrarte E, Margareto J, Novo FJ, Marti A and Martinez JA: UCP1 muscle gene transfer and mitochondrial proton leak mediated thermogenesis. Arch Biochem Biophys 404: 166-171, 2002.

17. Crespo A, Peydro A, Dasi F, Benet M, Calvete JJ, Revert F and Alino SF: Hydrodynamic liver gene transfer mechanism involves transient sinusoidal blood stasis and massive hepatocyte endocytic vesicles. Gene Ther 12: 927-935, 2005.

18. Hodges BL and Scheule RK: Hydrodynamic delivery of DNA. Expert Opin Biol Ther 3: 911-918, 2003.

19. Bouillaud F, Couplan E, Pecqueur C and Ricquier D: Homologues of the uncoupling protein from brown adipose tissue (UCP1): UCP2, UCP3, BMCP1 and UCP4. Biochim Biophys Acta 1504: 107-119, 2001.

20. Sokolova IM and Sokolov EP: Evolution of mitochondrial uncoupling proteins: novel invertebrate UCP homologues suggest early evolutionary divergence of the UCP family. FEBS Lett 579: 313-317, 2005.

21. Goglia F and Skulachev VP: A function for novel uncoupling proteins: antioxidant defense of mitochondrial matrix by translocating fatty acid peroxides from the inner to the outer membrane leaflet. FASEB J 17: 1585-1591, 2003.

22. Rial E, Aguirregoitia E, Jimenez-Jimenez J and Ledesma A: Alkylsulfonates activate the uncoupling protein UCP1: implications for the transport mechanism. Biochim Biophys Acta 1608: 122-130, 2004.

23. Dulloo AG, Seydoux J and Jacquet J: Adaptive thermogenesis and uncoupling proteins: a reappraisal of their roles in fat metabolism and energy balance. Physiol Behav 83: 587-602, 2004.

24. Jezek P, Zackova M, Ruzicka M, Skobisova E and Jaburek M: Mitochondrial uncoupling proteins - facts and fantasies. Physiol Res 53: S199-S211, 2004

25. Fink BD, Reszka KJ, Herlein JA, Mathahs MM and Sivitz WI: Respiratory uncoupling by UCP1 and UCP2 and superoxide generation in endothelial cell mitochondria. Am J Physiol Endocrinol Metab 288: E71-E79, 2005

26. Speakman JR, Talbot DA, Selman C, Snart S, McLaren JS, Redman P, Krol E, Jackson DM, Johnson MS and Brand MD: Uncoupled and surviving: individual mice with high metabolism have greater mitochondrial uncoupling and live longer. Aging Cell 3: 87-95, 2004.

27. Vincent AM, Olzmann JA, Brownlee M, Sivitz WI and Russell JW: Uncoupling proteins prevent glucose-induced neuronal oxidative stress and programmed cell death. Diabetes 53: 726-734, 2004.
28. Baumruk F, Flachs P, Horáková M, Floryk D and Kopecky J: Transgenic UCP1 in white adipocytes modulates mitochondrial membrane potential. FEBS Lett 444: 206-210, 1999.

29. Son C, Hosoda K, Ishihara K, Bevilacqua L, Masuzaki H, Fushiki T, Harper ME and Nakao K: Reduction of diet-induced obesity in transgenic mice overexpressing uncoupling protein 3 in skeletal muscle. Diabetologia 47: 47-54, 2004.

30. Palou A, Pico C, Bonet ML and Oliver P: The uncoupling protein, thermogenin. Int J Biochem Cell Biol 30: 7-11, 1998.

31. Nedergaard J, Golozoubova V, Matthias A, Asadi A, Jacobsson A and Cannon B: Biochim Biophys Acta 1504: 82-106, 2001.

32. Nedergaard J and Cannon B: The 'novel' 'uncoupling' proteins UCP2 and UCP3: What do they really do? Pros and cons for suggested functions. Exp Physiol 88: 65-84, 2003.

33. Huang SG: Binding of fatty acids to the uncoupling protein from brown adipose tissue mitochondria. Arch Biochem Biophys 412: 142-146, 2003.

34. Madsen K, Ertbjerg P and Pedersen PK: Calcium content and respiratory control index of isolated skeletal muscle mitochondria: effects of different isolation media. Anal Biochem 237: 37-41, 1996.

35. Watanabe N, Kamei S, Ohkubo A, Yamanaka M, Ohsawa S Makino $\mathrm{K}$ and Tokuda $\mathrm{K}$ : Urinary protein as measured with a pyrogallol red-molybdate complex, manually and in a Hitachi 726 automated analyzer. Clin Chem 32: 1551-1554, 1986.

36. Arechaga I, Raimbault S, Prieto S, Levi-Meyrueis C, Zaragoza P, Miroux B, Ricquier D, Bouillaud F and Rial E: Cysteine residues are not essential for uncoupling protein function. Biochem J 296: 693-700, 1993

37. Estabrook RW: Methods in Enzymology, vol. 10. Estabrook RW and Pullman ME (eds). Academic Press, New York, pp41-47, 1967.

38. De Geest B, Van Linthout S and Collen D: Sustained expression of human apo A-I following adenoviral gene transfer in mice. Gene Ther 8: 121-127, 2001.

39. Ricquier D, Raimbault S, Champigny O, Miroux B and Bouillaud F: Comment to Shinohara et al, FEBS Letters 293 (1991) 173-174. The uncoupling protein is not expressed in rat liver. FEBS Lett 303: 103-106, 1992.

40. Kramer MG, Barajas M, Razquin N, Berraondo P, Rodrigo M, Wu C, Qian C, Fortes $\mathrm{P}$ and Prieto J: In vitro and in vivo comparative study of chimeric liver-specific promoters. Mol Ther 7: 375-385, 2003

41. Liu F, Song YK and Liu D: Hydrodynamics-based transfection in animals by systemic administration of plasmid DNA. Gene Ther 6: 1258-1266, 1999 .

42. Nicholls DG and Rial E: Methods: Measurement of proton leakage across mitochondrial inner membranes and its relation to protonmotive force. Methods Enzymol 174: 85-94, 1989.

43. Rousset S, Alves-Guerra MC, Mozo J, Miroux B, CassardDoulcier AM, Bouillaud F and Ricquier D: The biology of mitochondrial uncoupling proteins. Diabetes 53: S130-S135, 2004.

44. Rasmussen HN and Rasmussen UF: Small scale preparation of skeletal muscle mitochondria, criteria of integrity, and assays with reference to tissue function. Mol Cell Biochem 174: 55-60, 1997.

45. Kaji DM: Effect of membrane potential on $\mathrm{K}-\mathrm{Cl}$ transport in human erythrocytes. Am J Physiol 264: C376-C382, 1993.

46. Takaki M, Nakahara H, Kawatani Y, Utsumi K and Suga H: No suppression of respiratory function of mitochondrial isolated from the hearts of anesthetized rats with high-dose pentobarbital sodium. Jpn J Physiol 47: 87-92, 1997.

47. Jarmuszkiewicz W, Antos N, Swida A, Czarna M and Sluse FE: The effect of growth at low temperature on the activity and expression of the uncoupling protein in Acanthamoeba castellanii mitochondria. FEBS Lett 569: 178-184, 2004.

48. Cadenas S, Echtay KS, Harper JA, Jekabsons MB, Buckingham JA, Grau E, Abuin A, Chapman H, Clapham JC and Brand MD The basal proton conductance of skeletal muscle mitochondria from transgenic mice overexpressing or lacking uncoupling protein-3. J Biol Chem 277: 2773-2778, 2002. 